Citation: Okyayuz, A.S. (2021). Food for Thought on Conducting Research Projects on Media Accessibility During the Covid-19 Pandemic and the New Normal. Journal of Audiovisual Translation, 4(2), 62-82. https://doi.org/ 10.47476/jat.v4i2.2021.190

Editor(s): P. Orero \& D. Hernández Falagán

Received: April 20, 2021

Accepted: October 10, 2021

Published: October 30, 2021

Acknowledgement: This special issue is related to the $\mathrm{H} 2020$ grant no. 825585 HELIOS A Context-aware Distributed Social Networking Framework.

Copyright: (C2021 Okyayuz. This is an open access article distributed under the terms of the Creative Commons Attribution License. This allows for unrestricted use, distribution, and reproduction in any medium, provided the original author and source are credited.

\section{Food for Thought on Conducting Research Projects on Media Accessibility During the Covid-19 Pandemic and the New Normal}

\section{Ayşe Şirin Okyayuz ${ }^{\bowtie}$}

Deprtament of Translation and Interpreting

Hacettepe University

\begin{abstract}
The following practice report is based on observational experiences of a project group running a research project on accessibility during the COVID-19 pandemic. The project aimed to provide accessibility using plain language in children's programs on a public television channel. The project included three groups of end-users: Deaf, hard of hearing, and visually impaired children. An overview of the project is presented to provide background for the practice report. The second part of the report deals with changes encountered in the running of the project during the pandemic: compensating for the lack of interactivity, social interaction and collective experience; using video conferencing; monitoring research; at-home research spaces and technological availability; network availability and performance; dealing with home computers; communication load; workload and work-life balance. Some key concepts of actor-network theory are used to analyse new actors, networks and shifts encountered in the process of implementing the project in the "new normal" in comparison to its planned implementation pre-COVID-19. In conclusion, a summary of possible options is cited to provide food for thought in running such projects.
\end{abstract}

Key words: media accessibility projects, Deaf, hard of hearing, visually impaired, child users, children's programs, New Normal, COVID-19.

\irinokyayuz@hacettepe.edu.tr, https://orcid.org/0000-0001-7512-2764 


\section{Introduction}

The following practice report details the running of a research project investigating the use of plain language in providing accessible programs to child users with disabilities (Deaf, $\mathrm{HoH}$, visually impaired) implemented during the summer of 2020 which coincides with the beginning of the COVID19 pandemic in Turkey.

In this period, most people were trying to adapt to living and working within the confines of their homes. We had relatively little experience in dealing with the very specific physical, psychological and technological limitations; not much was known about running a research project in the new normal.

The initial part of the article details the research project itself to provide background for the changes detailed in the second part of the study. The article does not concentrate on the project itself, rather it aims to highlight the ways in which the team compensated for the changes during the COVID-19 pandemic. Some of the issues referred to in the second part of the study are linked to group composition and profile of participants in media accessibility projects, whereas others relate to communication problems and various project processes that that had to be changed because of the pandemic.

The report has not been based on empirical research but on the observational experiences of the members of the project. The conclusion puts emphasis on the concept of the "new normal" in the running of media accessibility research. In the following section an overview of the project is given to provide backdrop against the changes introduced during the pandemic. The outputs, the details of the process, the data collected, and the quantitative and qualitative analyses may be found in the online project report. ${ }^{1}$

\section{An Overview of the Project}

The project "Providing Accessibility in Children's Programs Aired by the TRT Çocuk Channel of Turkish Radio Television Corporation for Visually Impaired, Deaf and Hard of Hearing Children (ages 3-17)" (see: SEBEDER, Projelerimiz, TRT Çocuk Kanalı Sağır, İşitme Engelli Ve Görme Engelli Çocukların Televizyon Programlarına Engelsiz Erişimi Projesi 2021b) is a research project investigating plain language in SDH, signed language interpreting, and audio description in the The Turkish Television and Television Corporation (see: TRT, 2021; TRT Çocuk channel.). Recent research has highlighted the importance of the use of plain language in accessibility practices (see: EASIT, 2018-2021; Matamala, 2021; EASIT, 2021; Jones \& Williams, 2017; Boldyreff et al., 2001).

${ }^{1}$ http://sebeder.org/TRT Cocuk Kanali Sagir Isitme Engelli Ve Gorme Engelli Cocuklarin Televizyon P rogramlarina Engelsiz Erisimi Projesi-1707.html\#gallery 
The project aimed to supply Turkish media providers, translators/interpreters and editors with process-focused guidelines that would help to provide accessibility for child end-users. The research group was asked to come up with a project that would ensure: a) quality from the start, b) researchbased validation with user-centric data (feedback from a representative group of the audience), and c) high quality accessibility during the COVID-19 pandemic.

The TRT (the client) had been considering airing accessible programs for children but was impeded by several factors: a) (as a public broadcaster) they did not have the knowhow necessary to ensure quality in accessibility for children; b) they did not have professional teams to produce accessible versions; and c) they wanted to make sure that if they were to invest (financially and otherwise) in this venture it would be successful in meeting the needs of the end-users. Thus, they outsourced the project.

SEBEDER (2021), a leading NGO in accessibility practices collaborating with media providers, in-house translators/interpreters, editors, technical staff and the communities of end-users with disabilities, was asked to conduct the project. SEBEDER had previous experience with producing accessible versions of media products for children (i.e., signed language video books for Deaf children; accessible course material for the Deaf and $\mathrm{HoH}$; audio described journals for visually impaired children) and had already conducted several projects with academics (see: SEBEDER Projelerimiz, 2021). The NGO is also the primary producer of accessible products on the Turkish market. This project produced several outputs:

a) The accessible versions (audio description, sign language interpreting, SDH) of 9 shows (three episodes each, a total of 27 episodes). The TRT provided the selected corpus which was representative of their broadcasting repertoire and included different genres appealing to different age groups such as programs encouraging children in arts and crafts, dubbed foreign cartoons, original TRT productions teaching children about math, etc.

b) A guideline document including information about:

- the profile of the potential production team (translators, interpreters, editors, technical staff);

- the workflow, responsibilities and limitations;

- the approach, including the relevant language/culture-specific translation strategies within the parameters (limitations and options) of audio-visual translation.

c) Focus group work on Deaf and $\mathrm{HoH}$ children aged 6+ for SDH, Deaf children aged 3-6 and 6+ separately for signed language interpreting, and the same age groups for audio description. The audience classification was a top-down variable given by the client. 
Part of the project's objective was to point out the importance of accessible media, especially at a time when persons with disabilities (who are in the best of times segregated from the wider society) were further segregated by the confinement and limitations brought on by COVID-19 (for research on COVID-19 impact on disabled communities see: Sabatello et al., 2020).

The project was implemented by a small interdisciplinary(?) group of experts in three stages.

a) The first stage of the project aimed at mapping out accessibility through using plain language for children in the Turkish setting. The central questions were: What words, structures, concepts, or visuals are easily recognized and understood by children? How do children differ from adults in terms of processing information? What can constitute plain language for different child end-user groups? The project group working on this initial stage included: authors and translators of children's books, audiodescribers for child-user products, sign language interpreters for child audiences, researchers on bilingual education for Deaf and $\mathrm{HoH}$ children, academics specializing in pre-school and early child education and experts in child cognitive development.

b) The second stage of the project aimed at mapping out how a plain language text (in line with norms set by the above-mentioned team) could be composed in the three translation settings $(S D H, A D, S L I)$. The central questions were: What are the pillars of the approach for translating/interpreting accessible products for children? What language/culture-specific strategies can be used in SDH, audiodescription, or sign language interpreting? How are translators, audiodescribers, or interpreters to produce accessible media products? The group working at this stage of the project included: translators of children's books; subtitlers and audiodescribers for child-user products, sign language interpreters for child audiences; Deaf and visually impaired editors with experience in working with child users.

c) The third stage of the project was about ensuring quality in view of the specific setting, potential technical limitations and other restrictions. Where child users are concerned, parental consent is always necessary; also, the focus group study needs to be fashioned in line with the child's capabilities. The focus group work was overseen by experts in child cognitive development. Deaf signers were used in communicating with Deaf children. The method used was similar to a semi-structured interview with a focus group. The sessions were recorded with permission from the parents of the children. Eye-tracking research was not possible as we were on lockdown, so comprehension questions were central and the questions also referred to "enjoyment" (did the child user like the product, would s/he want more products etc.) The focus group was designed to include variables such as age, gender, place of residence, different educational background, etc.

The project outputs concentrated around the central idea of the utilization of plain language. The questions to be answered were: 1 ) what is plain language accessibility for Turkish and the Turkish culture; 2) how can we ensure it is implemented (a checklist of do's and don'ts); 3 ) what are the 
technical considerations (number of words, syllables per word, lines etc.); 4) how do we implement it in media products for children; 5) what professionals/workflows are necessary for its production; and 6) how does it benefit the end-users?

The initial discussions with experts in different fields with varied experience revealed that what we considered plain language had multiple dimensions ranging from the purely linguistic (from the morphological strata to discourse) through the cultural (differences between foreign products and Turkish products) to the technical (i.e., placement, colour, etc., of subtitles, potential for personalizing audio description, the specifications for sign language windows).

The project group concluded that plain language use involves multiple layers (see: IPLF, 2021; ISO/IEC WD 23859 Guidance on making written text easy to read and easy to understand) and requires a specific perspective in working with audio-visual material within the scope of the project. The project group found the following dimensions to be important in working on plain language in audio-visual content: the specific language and culture, language in general and linguistic abilities of specific age groups, genre of products, and presentation of plain language.

Based on previous research and experience, the project group decided that the guidelines should encompass all dimensions mentioned. The group accepted that initial guidelines were necessary but would need to be developed and enriched as the practice grew. The guidelines also allowed media providers to understand the expertise needed in the implementation of such an initiative and the intricacies of the process.

The media provider assured the team that set technical specifications could not be altered at this point (e.g., the fonts could not be enlarged, italics could not be used, colours could not be changed, etc.), but this would remain a priority which they would investigate as the practice evolved.

The group outlined plain language for Turkish child end-users and produced a guideline on general principles to be embraced. The guidelines included common occurrences, templates in the program types and ways to deal with generic issues.

The guidelines also included parameters which would guide translators and interpreters in selecting the most effective strategy (in recitations like talk-aloud-protocols) with constant references from experts to the child end-user's average cognitive abilities (thus legitimising the parameters for the translator/interpreter to internalize the act).

The guidelines clearly stated that they only provide suggestions (a rationale for the approach to be embraced by the professionals) and cannot be a comprehensive text mapping all the so-called good practices.

All three accessible versions of some episodes were piloted. The focus group work conducted at this stage focused on two points: whether the children accessed the products (checked with 
comprehension questions and comments); and whether they enjoyed the products (checked with semi-structured interviews).

The first point was important to verify whether the project had yielded results. But it also highlighted that expectations from this initial project should not be unrealistically high. For example, the project could not have been expected to fully succeed with Deaf children accessing SDH. They were at an age when their hearing peers had mastered reading skills at a certain rate but the children with disabilities in the focus group were falling behind. This was a problem to be addressed by educational institutions in Turkey. Furthermore, the use of (plain language) subtitles would be useful in the long run for language acquisition and improvement of linguistic skills (see: Danan, 2004; Lertola, 2015; Talavan, 2006, Vanderplank, 2010, 2013, 2016; McLoughlin \& Lertola, 2014; Kothari, 2008), but a single project could not be expected to significantly improve linguistic skills.

Data revealed that sign language versions were accessible. Deaf children almost unanimously deemed these versions understandable. There were some comments on the speed of delivery of the sign language. These comments were reintegrated into the guidelines setting stricter speed limitations (number of signs per minute).

Data revealed that the audio described versions were well received. Almost unanimously, the group of child end-users found that they understood the products and enjoyed the experience. Comments from sighted parents also highlighted certain issues. To present a few examples: "my child was engrossed in the cartoon and able to concentrate on listening to the product as $s /$ he understood everything as the product seemed to be designed with that aim." Mothers also reported that their children usually asked questions while listening to audio described products not designed for them, but after talking with their children about these new products they realized the children had been able to "visualize the details in their mind's eye" - they felt this was beneficial for their development and future self-sustainment. Audio description research also included blind parents with blind children and blind parents with sighted children and the data from these groups also revealed interesting facts. For example, some blind parents felt that since they were able to answer the (sighted) child's questions and share the experience, they did not feel inadequate in meeting their child's needs.

Data revealed that plain language SDH was successful in providing accessible versions for the majority if not all the children; they had learnt new words and concepts; they wanted more products they found enjoyable. Some children commented on hard-to-read character names and place names tripping them up.

In conclusion the project had shown us that:

- Since in the case of plain language use the focus is on language (and culture and the realities of the country in which the language is used), both country and language specific research is of extreme importance. But some basic guidelines (or, better yet, approaches) will be partially 
universal, so standards have to be developed as the work in progress has already revealed (see: ISO/WD 24495-1 Plain language)

- One suggestion to the media providers who are also producers or buyers of programs was to create accessible versions from the start or to work with teams that would advise producers in the production of versions to which accessible tracks could be added.

\section{What Changed?}

The following section details the changes in the process of running the project summarised above when it turned out that pre COVID-19 research habits did not conform to COVID-19 realities. As previously stated, the information is based solely on the observations and experiences reported by the project group.

They key argument is that when online communication replaced other modes of communication during the pandemic, this did not imply work as usual. Some of the points mentioned below to support this argument are cultural (or country specific) so these may only be minimally relevant or even irrelevant in other settings. Furthermore, since some of the project group members had previous experience working together, the project design (especially information flow) was embedded in their previous experiences (for example, the ways in which hearing academics had communicated successfully with Deaf editors in past projects). Thus, if other options are habitually used by other project groups, these changes may not be meaningful to all researchers, but they will be meaningful to researchers designing projects to be run during the pandemic. The changes are presented in the following section with reference to key concepts taken from Bruno Latour's actornetwork theory (ANT), which may help us consider that all social processes take place in constantly changing technical and social networks of relationships.

Before we move on to detail the changes, it is important to explain that changes occurred due to various variables.

The contributors or researchers involved in the project had different profiles. All actors had previous experience in such projects and there was a flow of information and work (which can be explained as agencies for communication and collaboration) that they were used to. During the pandemic the major actors did not change but there was a shift in the agencies of communication and collaboration used. Thus, the first challenge of running a research project on media accessibility during COVID-19 relates to accessibility due to project group profiles and the lack of experience in the use of agencies for communication and collaboration.

There were three subgroups in the project. 
Table 1.

Project Groups

Group 1: Core reserach group Group 2: Experts participating Group 3: Focus groups

in certain stages of the project

- NGO representatives.

- Translators/Interpreters of SDH, AD, SLI.

- Editors of SDH, AD, SLI.

- Researchers of SDH, AD, SLI.

INCLUDES: Deaf and Hard of Hearing and visually impaired participants.
- Experts in child development and communication.

- Experts in children's literature.

- CODA interpreters.

- Technical staff.
- Deaf and Hard of Hearing children ages 3-17 (separated into two groups).

- Visually impaired children ages 3-17 (separated into two groups).

- Visually impaired parents of sighted children.

- Deaf parents of Deaf children, parents of Deaf children who were hearing.

- Parents of visually impaired children who were visually impaired, visually impaired parents with sighted children.

INCLUDES: Deaf and Hard of Hearing and visually impaired participant.

Source: Author's own work.

The core research group designates those contributors who were expected to follow each step of the process. In some meetings, this group was further fragmented into smaller groups working on audio description, SDH and signed language respectively. The focus group participants contributed to the final stage when the products had been completed and feedback was needed. The core research group consisted of academics, NGO representatives, translators, interpreters, editors and other experts. Some of the participants in this group were visually impaired or Deaf, others were not. The wider group included CODA's and Deaf interpreters and technical staff. The focus group included Deaf and Hard of Hearing children ages 3-17 (separated into two groups), visually impaired children ages 3-17 (separated into two groups), visually impaired parents of sighted children, Deaf parents of 
Deaf children, parents of Deaf children who were hearing, parents of visually impaired children who were visually impaired, visually impaired parents with sighted children.

The above given participants contributed to different stages of the project (detailed in the project overview).

Table 2

Stages of the Project

\begin{tabular}{ccc}
\hline Stage 1 & Stage 2 & Stage 3 \\
\hline Group 1 & Group 1 & Group 1 \\
Group 2 & Selective experts from Group 2 & Selective experts from Group 2 \\
& & Group 3 \\
\hline
\end{tabular}

Source: Author's own work.

It is important to note that the profiles of the participants in the groups varied in terms of how they accessed and provided information either due to their disabilities and abilities or due to their ages and disabilities (for example, children and parents with disabilities in the focus group).

The rule of thumb in previous projects was to provide accessible settings throughout the project. The core research group composition presented above implies that the project itself is accessible from the start, as all experts with disabilities had to be its integral part.

This is not new for researchers who habitually work in such groups. But the fact that the main medium of communication shifted (from one-on-one contact in previous congregational settings to the use of other communication and collaboration media) and other factors had to be taken into account (to be detailed) did cause challenges.

The changes that occurred during the pandemic may be grouped (very roughly) under several headings:

- the way the project research group functioned (changes to the actors, agencies and media used in the new communication and collaboration network);

- the way the user centric data gathering functioned (online focus groups, limitations and difficulties in terms of accessing new collaboration networks);

- the way in which the project had to be drafted and run (not being able to use certain agents and technological tools, etc.).

The following section details the challenges and subsequent changes brought on by the heavy reliance on technology and online communication during the pandemic. 
The following issues came to light when compiling experiences and observations from the project group: using home computers and infrastructure; online communication media; availability and coordination of actors; controlling focus group processes; work-load of actors; online communication etiquette; work-flow design.

These changes are detailed using the concepts of Actor-Network Theory. Actor-Network Theory (ANT) is, in the broadest terms, an approach to research that pivots away from humanism to focus on dynamic assemblages of humans and nonhumans. Developed in the social studies in the second half of the 20th century, ANT is also used in other fields of social inquiry. ANT explains that the social effect(?), like all other effects, is an enactment of heterogenous assemblages of human and nonhuman entities. The role of the researcher is to trace these processes of assemblage and reassemblage. The objective in the ANT approach is to understand how these things come togetherand manage to hold together-to assemble collectives or "networks." In this sense ANT may be used to analyse change in certain settings and answer questions about the different kinds of connections and associations created among things. In line with this idea, the second part of the report explores the changes that occurred within the network (which was not a set entity in the first place but based on certain routine behaviours and approaches, presumptions and habits). There was a certain 'notion' of how things worked in the setting described but when actors were added, or the positioning of actors or their roles changed, or the intermediacy or mediation of their roles altered, this led to an overall shift. For want of a better description, a reassemblage occurred.

The central concepts to be used for the scope of the report may be explained as follows: In ANT actors are defined as anything that is capable of mobilizing a network of different allies regardless of its status as human or nonhuman (Akrich \& Latour, 1992, p. 259). For the scope of the report under discussion, 'actors' are taken to mean both human and non-human components of the network.

In ANT a network is conceptualized as a "group of unspecified relationships among entities of which the nature itself is undetermined" (Callon, 1993, p. 263). In line with this point, ANT is concerned with exploring how networks come into existence, looking into which relations exist, how those relations are sustained, how actors come together to constitute and maintain a network, how various (heterogenous) parts of a network evolve into an entire network and how networks maintain impermanent stability (Erkazancı Durmuş, 2020, pp. 43-44). These questions are also significant for the present study, since they reveal the shifting character of and constant relationships between the networks the report focuses upon. For the scope of the paper, there are stacked networks within the larger network. The issue with multiple actors with differing profiles is that the communicative interactional network of such a setting can be visualized from multiple perspectives according to the specificity of work to be undertaken at each stage. While there are instances when smaller groups communicate within themselves, there are also instances where interaction with the larger group becomes necessary. This means that we have mediated communication networks (interpreted, translated), and semi-direct (Zoom-mediated) communication networks. There are also instances when all of these activities are happening all at once where all participants meet over Zoom. The role of the Zoom actor also changed from a communicative tool, to a tool that facilitates an actor 
mediation activity to other actors. In each interaction network, the scenario and the positioning of roles differs. For example, whereas in a setting where the Deaf interpreter, the CODA interpreter and focus group participants are running the focus group (asking the child end-users the questions) the dominant linguistic actor is sign language and the child expert who does not know sign language is delegated to a role of an intermediary where she is a vessel passing on the information produced by the large network to the CODA interpreter when necessary. But when drafting the approach to be taken in conducting the focus groups with the child participants and parents, the information she relays and her voice is central and the CODA interpreter is an intermediary relaying her content (another actor) to the Deaf interpreter (who is an active/passive participant) receiving the instructions. Once the Deaf interpreter has mediated this content, her role shifts to the main mediator in the focus group sessions as her language is a major actor. In each change outlined in the following section the shifts in position and power of the actors and their interaction with newer actors (Zoom etc.) are presented with reference to networks.

Another core ANT concept is enrolment (see: Sarker \& Sidorova, 2006), which identifies how different actors comply with the roles they have been given and get accustomed to the interests and working conditions of the other actors enrolled in the network. Within the report, roles are taken to point to concrete work (translates, interprets, mediates etc.). In defining roles, the central question is 'what does this actor do' and what the 'assumed aim-work load' of the use of the specific actor is within the network.

In this context, the positioning of actors is closely related to interessement, another significant moment described as part of the networking process (see: Calloon, 1986). When various actors come together to negotiate the roles they assume within the network, the process of interessement commences. The primary actor of the network negotiates with others to persuade them that they will be able to fulfil their own agendas when they get enrolled in the network. Within the scope of the report, it is possible to see that when the actors take positions, they question whether their roles have changed and whether their existence has been foregrounded or gained power (importance) in the specific change to the network.

The interaction between different actors gains further visibility within the process of mobilization (Calloon, 1986, p. 203). This process drives the maintenance of the network by ensuring that all the actors act according to the interests of the broader network for which they come together. When referring to interaction, this may point to communicative interaction between human and nonhuman actors or the interaction between human and non-human actors not solely for communicative purposes (how they fit into the broader network).

As will be outlined below, the project was initially designed to be implemented as the old design (old actors and old networks). When we compare this with what was actually implemented during the time frame referred to (new actors, new networks) it is clear that there are several changes. Within the scope of the project, broadly speaking, there were new actors to be reckoned with, there were also shifts to the positioning (the importance, the centrality of old actors) and composition of old 
actors, and the design of new networks brought on by the two changes listed above. These can be explained as follows.

\subsection{New Actors: Networks}

\subsubsection{Designing a New Actor: Online Focus Group Research}

Being limited to online research affected data gathering procedures and means. Both the focus group composition and the basic tools (interviews, comprehension questions) to be used did not change. But some features did change. For example, since the products had been prepared for television, they should ideally be accessed on this device. During the pandemic, links were provided to watch the products at home on computers which were to be connected to television screens. This meant that the group could not control the devices which the participants chose to watch the products. Today, scholars underline that our traditional view of broadcasting needs to change to support object-based broadcasting and use of personalization and the importance of providing high quality accessibility through personalization on multiple platforms (Orero, 2021).

Also, viewing times and frequencies of the focus group could not be ideally monitored. The focus group participants were asked to view the products individually and from start to finish in one sitting. They were also asked to view each product only once as this would be their experience if the programs had been broadcast on television. The project team could not check if in each case the children complied with these restrictions as in many cases the children were accessing the programs on their own.

The signing of the informed consent forms also caused challenges. Primarily separate sessions had to be set with each participant where the forms were either read to (the visually impaired) or translated for (the Deaf) participants as no work could start without consent. The informed consent and the data gathering were managed by SEBEDER and they had to come up with alternative strategies to deal with the changes.

Some research technologies could not be used online. For example, an eye tracking study could not be done as online eye tracking was not included in the budget. It was too risky and too costly during the pandemic to ask the participants to come in physically for eye tracking sessions (i.e., airing the room, working the correct filters on the equipment, getting people to come, access to facilities at universities, etc.).

Though there was a "focus group," this group (at a time when group congregation was not possible) evolved into a group where individuals were communicated with separately through internet calls. Although the use of internet video calls in qualitative interviews has been researched (Weller, 2015, 2017), there is no specific research on working with persons with disabilities. 
The use of online communication also affected the size of the focus group. During the pandemic each participant had to be contacted individually. Everything had to be explained from scratch and the same questions had to be answered.

\subsubsection{A New Actor: Online Communication Media}

The change in the main medium of communication was a central challenge to effective communication. The positioning of the online communication platforms, previously used as a supplementary mode of communication only when face-to-face communication was not possible, changed. These platforms now became central communication platforms.

For the scope of the project, platforms like Zoom were preferred since groups could share screens, chat, interact through audial and visual input. But these platforms were frequently unfamiliar to the members with disabilities in the project group. Furthermore, the platforms were not fully accessible. Zoom was used despite its challenges since the use of other platforms would have limited the type of information that could be shared (e.g., Skype). Previous research has revealed that Zoom is a relatively better tool to be used in certain research types (Archibald et al., 2019; Lo lacono et al., 2016).

Zoom provides accessibility support (see: Zoom - https://zoom.us/accessibility), but Turkish is not an option. Furthermore, accessibility features are not all available in free Zoom plans and packages. These need to be purchased. This is a problem for those actors who do not have the purchasing power or who cannot prioritize this purchase. Previous research in Turkey has shown that in general disabled individuals rank low on the employment scale and incomes are quite low (Genç \& Çat, 2013).

Thus, for example, some focus group participants did not have infrastructure to watch the material presented on television. Not all participants could use Zoom. Participants contributed through WhatsApp video calls, Skype and other such platforms. Each interaction had to be recorded. Also, since irrespective of the tool used, there had to be a systematicity in the relaying and gathering of content, the core group had to plan for every contingency.

\subsection{Shifts in the Positioning and Composition of Actors}

\subsubsection{A New Positioning of an Old Actor: Home Computers and Related Infrastructure}

Online communication is causally linked to access to technology. In the specific case of this project, at the start of the project (before the COVID-19 lockdown), the actors involved in stages 1 and 2 had always had access to work computers and internet. Although every actor had a personal computer and internet access in their home, the efficiency of these was never an issue. In recruiting the teams and the focus group (in the pre-COVID lockdown period) there was no initial questionnaire as regards the quality of their internet connection or the hardware on their computers (videos, microphones 
etc.), their knowledge about using certain platforms or the technology they had readily available. Home computers and internet were peripheral actors to be used by the participants in rare cases. But the positioning of this peripheral actor changed, and it became a central actor when all work was conducted on home computers and the internet.

In some cases, the project participants with disabilities in stages 1, 2 and 3 of the project did not have the purchasing power to use the latest technologies, computers and internet lines (for issues regarding digital divide, see: O'Halloran, 2020). For example, in stage 3 some computers used by the focus group participants did not have cameras or external microphones. Scholars in the field have voiced concerns about inequalities in access to technology. There has been research on how age, gender, living alone, concerns about Internet access, and Internet skills relate to changes in social contact during the pandemic. And furthermore, the use of digital media for social connection during a global public health crisis may be unequally distributed among citizens and may continue to shape inequalities (Nguyen et al., 2020). The purchasing power of the disabled participants, their inability to immediately procure new internet services and newer computers hindered communication and collaboration. This challenge can be labelled as limits to purchasing power which proved unequal among the participants. This did not add a new dimension to the network as the disparities in purchasing power did not occur during the pandemic. But, based on the changes in the positioning (moved from peripheral to central) of actors (technology and infrastructure) in the new normal, this became an issue.

\subsubsection{An Old Actor With a New Importance: Changes in the Workload of Actors}

The use of technology was also closely linked to workload and working times. The concepts of working hours and availability were also affected by the main mode of communication. Even though project teams from around the world may meet at any hour during the day, the general tendency is to schedule meetings during "office hours." Since the only line of communication was through these meetings or in writing, the meetings were longer since they were not supplemented with one-onone contact. Project members seemed to feel that everyone was "one click away" which would not have been the case if the group had congregated physically. Thus, people felt "on call" at all times (see: Chesley, 2010; for correlation between ICT and workload).

The use of online communication affected workload. Studies have been published proving a direct correlation between increase in workload and the use of technology (see: Sandoval-Reyes et al., 2019). In previous experiences since all the participants would have congregated in a single setting, for example, the sign language interpreter would relay information just once. It was not possible to ask everyone in the focus group to schedule the same time slot to congregate as the children's school times had been changed to two separate shifts according to their age groups. Furthermore, in many homes there was a single device for such communication and since the parents also used this device for work, it was harder to reach participants. The voluntary contributions to the project had to be scheduled at a time when the children did not have online courses, the parents where not working 
online as either they could not participate because they were busy or because the internet connection would not allow for several links from the same server. Most of the focus group work was done later in the evening (before the children's bedtimes) when parents had finished their own work. If this had been face-to-face or if the focus group members visited participant's homes, such hours would have been unacceptable. It was noted that not every focus group participant was as engaged in the process as they would have been had we congregated physically. Scholars of communication refer to this as "preparedness for online communication and interaction" (Kaufmann \& Vallade, 2021). It was clear that the change in the medium of communication implied that the project group had to adapt to "learning" a new means and style of communication and coordination (see Buchan et al., 2021). Though this sounds simple, it is not as clear cut as "you just do what you would have done in a face-to face meeting online." This requires at the very least some experience in using the technology and situating yourself in the setting (for details of comparison, see: Lee et al., 2011), which can be challenging for disabled participants (and others). In ANT terms there was an issue with enrolment. The project group had to come up with solutions to be designed and tested as the work progressed.

In working with researchers and participants with disabilities a frequent mantra is "I should know of everything if this is to serve my community." But communication in settings where there is no faceto-face contact is necessarily fragmented - not everyone could be present for all meetings and during all communication (e.g., phone calls). The prevailing tendency was to hold many repetitive meetings with small groups where one group of core individuals would repeat the same information. In the case of new input at each turn this became a vicious cycle. The core group would have to inform each participant individually, which led to a very intense telephone and WhatsApp video call traffic. Communication in writing was an option throughout the process, but it also led to problems especially with Deaf researchers. Not only were some of their (for example) WhatsApp messages not so easy to decipher due to their use of what essentially was a foreign language but sometimes shorter messages sent by other participants led to miscommunication since spoken Turkish was not their native language. Because of the above given facts, the project group ended up writing longer and more detailed messages than we would have if our main line of communication had not been restricted. This ties in with the issue of the maintenance of the network by ensuring that all the actors act according to the interests of the broader network for which they come together.

\subsubsection{An Increase in Actor Information Loads: Issues With Multiple Actor Involvement and Workflow Design}

The single use of online communication also affected workflow design. The use of a native speaker of sign language is common practice when communicating with the Deaf (Gall, 2015; Haug et al., 2017). In previous practice, since participants were adults and since the project researchers and the CODA interpreter where both present during the initial participant recruitment and also the focus group study, the project researcher was on hand to answer any questions and assist the interpreter 
during the process. In the case of the project, further coordination was necessary in this blended Deaf and hearing setting (see: Napier, 2011). Also, since we were dealing with children (variation in the cognitive abilities), the Deaf interpreter had to be further informed to be able to comprehend the project. This change ties in with the positioning of actors and is closely related to interessement, another significant factor described as part of the networking process.

\subsection{New Networks}

\subsubsection{A New Network for an Old Actor: Designing New Interaction Settings}

Interaction and communication among participants are important aspects of any project. In the project stage 1 in previous experiences with face-to-face interaction, there were smaller groups communicating simultaneously within a larger group. For example, when the interpreter is the dominant voice in the setting interpreting for the Deaf participant, other participants may whisper to each other, and this does not impede communication. But on Zoom there was only one audial channel for communication and two simultaneous voices would not be possible. In every instance there was one single voice, thus interaction was limited in this sense. Actors could use the chat feature on Zoom which meant that they were further distracted.

At this juncture options such as using multiple platforms for communication simultaneously or buying upgraded versions of the technology that could be used for interpreting became an option. As meetings progressed, participants became cognizant of what needed to be done and integrated this into the communication flow design.

Sensitivity was high (for potential negative feelings that people can experience in the current emergency period see: American Psychological Association, 2020; World Health Organization, 2020) and this was something that needed to be considered in ensuring full participation and team spirit if the project was to be run smoothly with input from all experts. Although such instances were easily resolved within the process, they entail potential problems with online sign language interpreting and online audiodescription which need to be more thoroughly researched since online communication became the main means of communication during the pandemic.

\subsubsection{Change in the Communication Network of Actors: Availability and Coordination of Actors}

At this juncture it is important to underline that previous research had been conducted in face-toface settings. Also, since most meetings were held in locations where audio describers and sign language interpreters were readily available (like the NGO Sebeder where these experts work as fulltime staff) there was never any difficulty in the process. 
But when the setting was relocated to Zoom, the availability of professionals became an issue. The professional audiodescribers and sign language interpreters who were a given actor in the previous settings now had to be found, and timing of meetings had to be arranged according to these actors as well. The core group had to take on an additional role of coordinating work according to the timetables set by translators and interpreters to help with the meetings.

\subsubsection{Change in the Constitution of a Peripheral Actor: Communication Etiquette Online}

Another point that came to light was the change in communication "etiquette." (For article on general Zoom etiquette see: Morris, 2020). Previously, when the group held online meetings with the visually impaired persons, none of the participants turned on their cameras. This was something the group had previously embraced. But when online communication became the only platform of communication during the pandemic, such etiquette was disregarded. This was a change that needed to be explained to the visually impaired participants.

Other issues also became relevant in communicating online (through Zoom), one of them being turn taking in a team of varied participants. The sighted participants were able to assess when someone was going to contribute, because if they were Deaf, they would start signing and if they were hearing they would turn on their microphone (followed by the prompt " $X$ is talking" at the top of the screen). The situation was different for the visually impaired unless at each instance the audio describer intervened ( $\mathrm{X}$ has turned on their microphone, $\mathrm{Y}$ has started signing). The audio describer had to cut in and explain ( $X$ has entered the meeting, $Y$ 's connection has dropped) or the visually impaired participants would be addressing someone who was not there or asking that someone be included when they were already present. With the signed contributions, since there was inevitably a short time lag between the participant's speech and the smallest meaningful unit that the interpreter had to spot before interpreting, there were many interruptions from the visually impaired participants in the core group. This caused a sense of unease within the group because one participant was always asked to "wait."

\section{As a Conclusion...}

One might question the reasons for conducting such a project during such a period. But, for one, we do not know when these measures change and work needs to continue, even though it is clear that this is not "work as usual" with the limitations brought on by Covid-19. Secondly, working on accessibility is particularly important for the dissemination of information, and the need for this becomes even more apparent during times like these.

Atkinson $(2020$, p. 1) states in his research on what has come to be referred to as the new normal that "[...] people had 'hacked' or innovated temporary design solutions to immediate problems out of sheer necessity." This is the case for most of us doing research during COVID-19 measures. The 
researcher underlines that, "[a]s things have progressed, and it is becoming clear that a quick fix is unlikely to happen, many of those temporary hacks have, as predicted, been replaced with more permanent, professionally designed alternatives." Another implication for media accessibility projects stemming from new requirements for interpersonal relations will inevitably affect the practice of design research itself. Participants are no longer likely to agree to lengthy face-to-face, semi-structured interviews with researchers. But to what extent these research tools, with all their rich underlying subtleties of body language and subliminal cues, can be satisfactorily substituted by the blunt instruments like Zoom or other online meeting spaces, is yet to be explored.

In conclusion, in the case the report discusses, it has been revealed that actor-networks were constantly evolving. Specific actors drove the process to enrol and mobilize others into an everchanging network. New actors became a prominent part of the process. As explained above, online communication media became a central actor with which all other human actors had to gain experience to interact and communicate. This also applied to the appearance of online focus group research which was a novelty for the project group.

Old actors gained new positions within the network as exemplified by the use of home computers and related infrastructure and the increasing importance of changes to workload and information load for actors.

New stacked networks also appeared for old actors as new interaction settings had to be designed due to varied group profiles, issues of availability and coordination. Communication etiquette had to be reformulated.

The new normal brings new issues for media accessibility research such as those outlined above: the addition of new actors to the process and their interaction within the network; a shift in the interactions between actors due to the shift in the position (peripheral, central) of the actor, and new networks within the process since the above given changes will necessitate new interactions due to change in sectors and positioning.

Also, media accessibility research must investigate new avenues and collaborate with other disciplines to either adapt technology to work with existing and traditional models that have been used thus far, or to come up with new solutions for work to continue efficiently.

The societal and behavioural changes that COVID-19 has wrought are certain to drastically alter the ways in which we conduct our work. There needs to be further careful thought and deliberation involved in the search for solutions. Tu et al., (2020) clearly reveal that this pandemic is not the last one we will be encountering, and long-term solutions need to be thought out in the context of research. The pandemic necessitated a sweeping transformation, which is likely to influence our life for the foreseeable future in the way people interact and operate (Griffin \& Denholm, 2020). 


\section{References}

American Psychological Association. (2020, April 15). Keeping your distance to stay safe. American Psychological Association. https://www.apa.org/practice/programs/dmhi/researchinformation/social-distancing

Akrich, M., \& Latour, B. (1992). A convenient vocabulary for the semiotics of human and nonhuman actors. In W. Bijker \& J. Law (Eds.), Shaping technology: Building society studies in sociotechnological change (pp. 259-264). MIT Press.

Archibald, M. M., Ambagtsheer, R. C., Casey, M. G. \& Lawless, M. (2019). Using zoom videoconferencing for qualitative data collection: Perceptions and experiences of researchers and participants. International Journal of Qualitative Methods, 18. https://doi.org/10.1177/1609406919874596

Atkinson, P. (2020). The new normal, The Design Journal, 23(5), 651-654, https://doi.org/ 10.1080/14606925.2020.1807719

Boldyreff, C., Burd, E., Donkin, J., \& Marshall, J. (2001). The case for the use of plain English to increase web accessibility. In Proceedings 3rd International Workshop on Web Site Evolution. WSE 2001, Florence, Italy, (pp. 42-48). https://doi.org/ 10.1109/WSE.2001.988784

Buchan, N. R., Adair, L., \& Chen X. (2021, January 19). Zoom work relationships are a lot harder to build - unless you can pick up on colleagues' nonverbal cues. The Conversation. https://theconversation.com/zoom-work-relationships-are-a-lot-harder-to-build-unless-youcan-pick-up-on-colleagues-nonverbal-cues-151541

Callon, M. (1986). Some elements of a sociology of translation: Domestication of the scallops and the fishermen of St. Brieuc Bay. In J. Law (Ed.), Power, action, and belief: A new sociology of knowledge? (pp. 196-223). Routledge.

Callon, M. (1993). Variety and irreversibility in networks of technique conception and adoption. In D. Foray \& C. Freemann (Eds.), Technology and the wealth of nations: Dynamics of constructed advantage (pp. 232-268). Pinter.

Chesley, N. (2010). Technology use and employee assessments of work effectiveness, workload, and pace of life. Information. Communication \& Society, 13(4), 485-514.

https://doi.org/10.1080/13691180903473806

Danan, M. (2004). Captioning and subtitling: Undervalued language learning strategies. Meta, 49(1), 67-77. https://doi.org/10.7202/009021ar

EASIT (Easy Access for Social Inclusion Training). (2018-2021). Erasmus + Strategic partnerships, 2018-1-ES01-KA203-05275.

EASIT. (2021). Multiplier Event 5 - Final Report. https://ddd.uab.cat/pub/infpro/2021/237169/EASIT ME5 report final.pdf

Erkazancı Durmuş, H. (2020). Pierre Bourdieu Sosyolojisi Işığında Türk Tiyatro Alanında Çevirinin Rolü ve Dostlar Tiyatrosunun Konumu [The role of translation and the position of Dostlar Theatre in the field of Turkish theatre: A Bourdieusian perspective]. Hiperyayın.

Gal, S. (2015). Politics of translation. Annual Review of Anthropology, 44, 225-240. https://doi.org/ 10.1146/annurev-anthro-102214-013806

Genç, Y., \& Çat, G. (2013). Employment of disabled people and social inclusion relationship. Akademik incelemeler Dergisi [Journal of Academic Inquiries], 8(1), 363-394.

Green, L., \& Mercer, S. (2001). Participatory research: Can public health researchers and agencies reconcile the push from funding agencies and the pull from communities? American Journal of Public Health, 91, 1-4. 
Griffin, D., \& Denholm, J. (2020, April 16). This isn't the first global pandemic, and it won't be the last. Here's what we've learned from 4 others throughout history. The Conversation. http://theconversation.com/this-isnt-the-first-global-pandemic-and-it-wont-be-the-lastheres-what-weve-learned-from-4-others-throughout-history-136231

Haug, T., Bontempo, K., Leeson, L., Napier, J., Nicodemus, B., Van den Bogaerde, B., \& Vermeerbergen, M. (2017). Deaf leaders' strategies for working with signed language interpreters: An examination across seven countries. Across Languages \& Cultures, 18(1), 107-131. https://doi.org/10.1556/084.2017.18.1.5

IPLF (International Plain Language Federation). 2021. Plain language definitions. IPLF. http://www.iplfederation.org/plain-language/

ISO/IEC CD 23859-1. Information technology - User interfaces - Part 1: Guidance on making written text easy to read and easy to understand. https://www.iso.org/standard/77178.html

ISO/WD 24495-1. Plain language - Part 1: Governing principles and guidelines. https://www.iso.org/standard/78907.html

Jones, N. N., \& Williams, M. F., (2017). The social justice impact of plain language: A critical approach to plain-language analysis. IEEE Transactions on Professional Communication, 60(4), 412-429. https://doi.Irg/10.1109/TPC.2017.2762964

Kaufmann, R., \& Vallade J. I. (2021). Online student perceptions of their communication preparedness. E-Learning and Digital Media, 18(1), 86-104. https://doi.org/10.1177/2042753020950873

Kothari, B. (2008). Let a billion readers bloom: Same language subtitling (SLS) on television for massliteracy. International Review of Education, 54(5-6), 773-780. https://doi.org/10.1007/s11159-008-9110-3

Lee, P., Leung, L., Lo, V-H., Xiong, C., \& Wu, T. (2011). Internet communication versus face-to-face interaction in quality of life. Social Indicators Research, 100. 375-389. https://doi.org.10.1007/s11205-010-9618-3

Lertola, J. (2015). Subtitling in language teaching: Suggestions for language teachers. In Y. Gambier, A. Caimi, \& C. Mariotti (Eds.), Subtitles and language learning (pp. 245-267). Peter Lang.

Lo lacono, V., Symonds, P., \& Brown, D. (2016). Skype as a tool for qualitative research interviews. Sociological Research Online, 21(12). https://doi.org/10.5153/sro.3952

Matamala, A. (2021). EASIT - toward hybrid access services in the audiovisual world. https://blogs.helsinki.fi/klaara-network/2021/01/04/anna-matamala-easit-toward-hybridaccess-services-in-the-audiovisual-world/

McLoughlin, L. I., \& Lertola, J. (2014). Audiovisual translation in second language acquisition. Integrating subtitling in the foreign-language curriculum. Interpreter and Translator Trainer, 8(1), 70-83.

Morris, B. (2020, January 1). Seven rules of zoom meeting etiquette from the pros. The Wall Street Journal. https://www.wsj.com/articles/seven-rules-of-zoom-meeting-etiquette-from-thepros-11594551601

Napier, J. (2011). It's not what they say but the way they say it. A content analysis of interpreter and consumer perceptions of signed language interpreting in Australia. International Journal of the Sociology of Language, 207, 59-87.

Nguyen, M. H., Gruber J., Fuchs J., Marler, W., Hunsaker, A., \& Hargittai, E. (2020). Changes in digital communication during the covid-19 global pandemic: Implications for digital inequality and future research. Social Media + Society, 1-6. https://doi.org/10.1177/2056305120948255 
O'Halloran, J. (2020, November 26). Inadequate home internet speeds contribute to 'digital divide' during UK lockdown. Computer Weekly.

https://www.computerweekly.com/news/252492714/Inadequate-home-internet-speedscontribute-to-digital-divide-during-UK-lockdown

Orero, P. (2021, March 24). Peter Pan and audiovisual translation [Webinar Presentation].Hacettepe Üniversitesi, Mütercim-Tercümanlık Bölümü Görsel-Işitsel Çeviri ve Projeler Seminer Series, Ankara, Turkey .

Sabatello, M., Landes, S., \& McDonald, K. (2020). People with disabilities in Covid-19: Fixing our priorities. The American Journal of Bioethics, 20(7), 187-190. https://doi.org/10.1080/15265161.2020.1779396

Sandoval-Reyes, J., Acosta-Prado, J. C., \& Sanchís-Pedregosa, C. (2019). Relationship amongst technology use, work overload, and psychological detachment from work. International Journal of Environmental Research and Public Health, 16(23), 4602. https://doi.org/10.3390/ijerph16234602

Sarker, S., \& Sidorova, A. (2006). Understanding business process change failure: An actor-network perspective. Journal of Management Information Systems, 23(1), 51-86.

SEBEDER (2021, June 1). Hakkımızda. Sebeder. http://sebeder.org/Hakkimizda-3.html

SEBEDER (2021a, August 1). Projelerimiz. Sebeder. http://sebeder.org/Projelerimiz-17.html

SEBEDER (2021b, August 1) TRT Çocuk Kanalı Sağır, Işsitme Engelli Ve Görme Engelli Çocukların Televizyon Programlarına Engelsiz Erişimi Projesi [TRT Children's Channel Project for Accessiblity to Programs for Deaf, Hard of Hearing and Blind Children]. Sebeder. http://sebeder.org/Ayrintili AltYazi Isaret Dili ve Sesli Betimleme-1706.html

Talavan, N. (2006). Using subtitles to enhance foreign language learning. Porta Linguarum: Revista Internacional de Didáctica de las Lenguas Extranjeras, 6. https://doi.org/10.30827/Digibug.30659

TRT - Turkish Radio and Television Corporation. (2021, August 1). TRT Hakkında. TRT. http://www.trt.net.tr/kurumsal/kurumsalyapi.aspx

TRT Çocuk (2021, August 1). TRT Çocuk Kanal Koordinatörlüğü. TRT. https://www.trt.net.tr/kurumsal/kurumsalyapidetay.aspx?id=54731bce4fa7cc0a6887f759

Tu, H., Tu, S., Gao, S., Shao, A., \& Shen, J. (2020). Current epidemiological and clinical features of COVID-19. A global perspective from China. Journal of Infection, 81(1), 1-9. https://doi.org/10.1016/i.jinf.2020.04.011

Vanderplank, R. (2010). Déjà vu? A decade of research on language laboratories, television and video in language learning. Language Teaching, 43(01), 1-37. https://doi.org/10.1017/s0261444809990267

Vanderplank, R. (2013). 'Effects of' and 'effects with' captions: How exactly does watching a TV programme with same-language subtitles make a difference to language learners? Language Teaching, 49(2), 235-250. https://doi.org/10.1017/s0261444813000207

Vanderplank, R. (2016). Captioned media in foreign language learning and teaching: Subtitles for thedeaf and hard-of-hearing as tools for language learning. Palgrave Macmillan

Weller, S. (2015). The potentials and pitfalls of using Skype for qualitative (longitudinal) interviews. Southampton, England - National Centre for Research Methods.

Weller, S. (2017). Using internet video calls in qualitative (longitudinal) interviews: Some implications for rapport. International Journal of Social Research Methodology, 20, 613-625.

World Health Organization (2020, April 15). Mental health and psychosocial considerations during the Covid-19 outbreak. https://www.who.int/docs/default-source/coronaviruse/mentalhealth-considerations.pdf 